\title{
SOBRE A INTERPRETAČ̃O AMBIENTAL DE PARÂMETROS ESTATÍSTICOS GRANULOMÉTRICOS: EXEMPLOS DE SEDIMENTOS OUATERNÁRIOS DA COSTA BRASILEIRA
}

\author{
WALDIR LOPES PONÇANO*
}

\begin{abstract}
The environmental interpretation of grain-size statistical parameters is a long and controversial matter in the geological literature. A trend has been devised by Folk \& Ward (1957) that indicates a relationship for mean size, standard deviation, skewness, and kurtosis in the $-3 \phi$ to $+3 \phi$ interval. This work furthers this investigation up to $+8 \phi$ through 588 samples from coastal environments. Results obtained are highly suggestive that standard deviation, skewness, and kurtosis are closely related to mean size.
\end{abstract}

INTRODUÇÃo A utilização de características granulométricas de sedimentos na descrição e identificação de ambientes deposicionais está para completar um século, podendo-se provavelmente assinalar como pioneiro o trabalho de Udden (1898, apud McLaren 1981). A literatura acumulada é numerosa e pode ser analisada sob vários aspectos; entre aquela consultada para a preparação deste ensaio, embora limitada, é possível assinalar alguns trabathos que marcaram mudanças importantes no tratamento do tema aqui abordado.

Assim, pode-se reconhecer que o trabalho de Inman (1952) forneceu as bases das estatísticas descritivas da granulometria, revistas por Folk \& Ward (1957), que estabeleceram fórmulas até hoje largamente usadas.

Ao trabalho de Sahu (1964) deve-se a introdução de uma abordagem quantitativa mais sofisticada na interpretação granulométrica pelo uso de análise discriminante. É possível que outros trabalhos desse tipo existissem à mesma época, entretanto nenhum teve a mesma repercussão.

Deve-se a Visher (1969) uma revisão bastante completa sobre a interpretação de processos deposicionais a partir de dados granulométricos. Talvez este artigo seja a última revisão do assunto vazada em linguagem geológica clássica e marque, na verdade, o limite a partir do qual o uso de técnicas de computação se tornou intensivo, com reflexos na facilidade e velocidade de tratamento de dados.

Os artigos de Swan et al. $(1978,1979)$ contêm uma revisão crítica muito pertinente sobre as estatísticas de granulometria enquanto o trabalho de MacLaren (1981) parece ser a mais recente tentativa de revisão voltada à interpretação de processos.

Uma apreciação geral sugere também que a maior parte da literatura se refere inicialmente a sedimentos arenosos e, mais tarde, a seixos; mais recentemente, os finos vêm sendo um pouco mais bem compreendidos, embora de modo ainda insatisfatório.

Neste ensaio será feita inicialmente uma revisão bibliográfica, essencialmente calcada na literatura internacional, seguida da apresentação de novos dados obtidos com amostras coletadas em diversos pontos da costa brasileira.

\section{DESCRIÇÃO DA GRANULOMETRIA DOS SEDIMEN-} TOS As características texturais de um sedimento podem ser referidas a um conjunto de estatísticas descritivas de sua distribuição granulométrica, associadas a tendências centrais (mediana, média e desvio-padrão) ou caudais (assimetria e curtose).

Atualmente, usam-se ainda com muita frequêencia as fórmulas propostas por Folk \& Ward (1957), criadas a partir das de Inman (1952) (Tab. 1). Aqueles autores realizaram um estudo sedimentológico num depósito fluvial fortemente bimodal (areia e cascalho), característica que os levou a considerar inadequadas as medidas de Inman (op. cit.) por se basearem em apenas dois ou três pontos da curva acumulativa, o que as tornariam insuficientes para descrever curvas não-normais.

Para Folk \& Ward (1957), a mediana deveria ser abando. nada por induzir a erros na apreciação dos sedimentos, visto que, por exemplo, seriam iguais os valores das medianas de um sedimento com $40 \%$ de cascalho e $60 \%$ de areia fina, e outro com $60 \%$ de areia fina e $40 \%$ de argila.

Para Folk \& Ward (1957), assimetria e curtose seriam fundamentais para se detectar bimodalidade na qual esta característica não aparece claramente. Mostraram, ademais, haver relações bem definidas entre diâmetro médio, desvio-padrão, assimetria e curtose, expressas pela equação de um helicóide.

Para Swan et al. (1978), há duas diferenças entre a estatística convencional e a aplicada em sedimentologia. A primeira vem de que, ao se agrupar os dados por classes de peso, resultam diferenças nos valores das estatísticas medidas em relação aos calculados a partir de classes por número de partículas. Outra diferença vem do uso da escala $\phi$ : os parâmetros calculados com dados convertidos a essa escala se relacionariam de modo simples aos dos dados não transformados no caso de populações normais (Sahu 1965, apud Swan et al. op. cit.), diversamente das populações não-normais. Para estudar o primeiro desses dois pontos, geraram amostras hipotéticas com dados para cada partícula, segundo distribuições normais padronizadas (média $=0$ e desvio-padrão $=1$ ), a partir das quais procederam a correlações entre as medidas segundo as fórmulas de Folk \& Ward (1957) e estatísticas para freqüência

* Instituto de Pesquisas Tecnológicas do Estado de São Paulo - IPT. Caixa Postal 7141, CEP 01000, São Paulo, SP, Brasil. Instituto de Geociências e Ciências Exatas, Universidade Estadual Júlio de Mesquita Filho. Campus de Rio Claro, CEP 13500, Rio Claro, SP, Brasil 
numérica não-agrupada, por um lado, e, por outro, com estatísticas para freqüência não-agrupada em peso. A primeira tentativa de correlação mostrou alta dispersão indicativa de que os dois conjuntos de valores cotejados descrevem diferentes características das amostras. A segunda mostrou boa correlação para diâmetros médios, decrescendo para desvio-padrão, assimetria e curtose, com grande dispersão nestes dois últimos parâmetros. Este resultado seria semelhante ao obtido por outros autores na comparação entre os métodos dos momentos e o gráfico, o que sugere que as medidas do método dos momentos para freqüência agrupadas em peso se constituem em boas estimativas dos valores não-agrupados correspondentes.

A conclusão de Swan et al. (1978) é a de que as medidas gráficas são boas para o diâmetro médio (exceto em amostras muito assimétricas ou com caudas pronunciadas nos $16 \%$ mais grossos ou mais finos) e desvio-padrão (com ressalvas para amostras medianamente selecionadas com caudas significativas nos $5 \%$ mais finos ou mais grossos). No caso da curtose e da assimetria, consideram que não se chegou a relações definidas entre os diferentes cálculos pois as medidas não-agrupadas são mais sensíveis às caudas que as medidas gráficas. Apontam ainda que as medidas gráficas não são muito sensíveis a populações significativamente não-normais; para sua aplicação, o peneiramento poderia ser feito em intervalos de $1 \phi$, pois a diminuição desse intervalo não aumentaria o alcance do método.

Swan et al. (1979) fazem sua avaliação do método de momentos para valores agrupados em peso e concluem que descreve melhor as populações que o método de Folk \& Ward (1957); a diferença entre os dois métodos seria maior no caso da assimetria e da curtose de curvas significativamente não-normais. Percebe-se que estas conclu- sões estão de certa forma contidas no trabalho anterior desses mesmos autores.

Mostram ainda que, no método de momentos, a precisão das estatísticas aumenta com a diminuição do intervalo de peneiramento de $1 \phi$ para $0,25 \phi$. Além disso, o truncamento da curva em $12 \phi$ não alteraria significativamente os resultados, ao contrário do truncamento em $9 \phi$.

Sob uma perspectiva bastante diversa dos trabalhos até aqui mencionados, Winkelmolen (1982) é de opinião que muito esforço foi despendido no aperfeiçoamento de estatísticas que pudessem descrever melhor as curvas granulométricas, de modo a se chegar a melhores interpretações genéticas. Tal esforço, porém, não teria sido muito útil, pois esta precisão pode melhorar a qualidade da descrição de fácies sem que ocorra o mesmo no que toca aos ambientes de sedimentação. Winkelmolen (op. cit.) salienta que a noção de "tamanho" (size) em sedimentologia pode envolver distintas dimensões: volume $\left(\mathrm{L}^{3}\right)$, peso (M.L.T. $\left.{ }^{-2}\right)$, superfície $\left(\mathrm{L}^{2}\right)$ e velocidade de deposição $\left(\right.$ L.T. $\left.^{-1}\right)$, que abrangem assim dimensões físicas diferentes e impossibilitaria deduções a respeito da mecânica deposicional. Ainda segundo este autor a descrição dos sedimentos deveria ser feita com parâmetros físicos puros, tais como massa e densidade, o que permitiria tirar conclusões válidas do ponto de vista físico e estatístico, com menor número de medidas. Assim, por exemplo, se $95 \%$ dos grãos de uma amostra, com massa e densidade determinadas, têm superfícies menores que grãos de mesma massa e densidade de uma segunda amostra, pode-se ter quase certeza que o meio de transporte tinha menor força de tração no segundo caso. Tal conclusão poderia basear-se na observação de 50 grãos e não na medição de dezenas de milhares.

Tabela 1 - Parâmetros estatisticos granulométricos, segundo Inman (1952) e Folk \& Ward (1967)

\begin{tabular}{|c|c|c|c|c|}
\cline { 2 - 5 } & Diâmetro médio & Desvio-padrão & Assimetria & Curtose \\
\hline $\begin{array}{c}\text { Inman } \\
(1952)\end{array}$ & $\frac{\phi 16+\phi 84}{2}$ & $\frac{\phi 84-\phi 16}{2}$ & $\frac{\phi 84+\phi 16-2 \phi 50}{\phi 84-\phi 16} \mathrm{e} \frac{\phi 95+\phi 5-2 \phi 50}{\phi 84-\phi 16}$ & $\frac{(\phi 16-\phi 5)-(\phi 95-\phi 84)}{\phi 84-\phi 16}$ \\
\hline $\begin{array}{c}\text { Folk \& Ward } \\
(1957)\end{array}$ & $\frac{\phi 16+\phi 50+\phi 84}{3}$ & $\frac{\phi 84-\phi 16}{4}+\frac{\phi 95-\phi 5}{6,6}$ & $\frac{\phi 16+\phi 84-2 \phi 50}{2(\phi 84-\phi 16)}+\frac{\phi 5+\phi 95-2 \phi 50}{2(\phi 95-\phi 5)}$ & $\frac{\phi 95-\phi 5}{2,44(\phi 75-\phi 25)}$ \\
\hline
\end{tabular}


Essas observações são interessantes, entretanto sua implementação a curto prazo não parece viável. Assim, levando em conta o atual estágio da ampla maioria dos laboratórios de sedimentologia, bem como a exposição referente aos trabalhos anteriormente mencionados, pode-se concluir, que as curvas granulométricas se deixam descrever bastante bem no que se refere aos métodos gráficos e de momentos pelo diâmetro médio e desvio-padrão, enquanto que assimetria e curtose fornecem valores de qualidade regular a medíocre, neste caso com significativa vantagem quando se usa o método de momentos.

Finalmente, levando em conta que as estatísticas podem simplificar demasiadamente a descrição da amostra, pode-se lançar mão de dados brutos, tais como porcentagens de argila ou areia, para completar a caracterização do sedimento considerado (Folk 1968). Nesse sentido, diagramas triangulares de classificação textural são úteis para transmitir uma descrição mais próxima da composição real do sedimento analisado e podem igualmente levar a interpretações ambientais (Asseez 1972).

\section{INTERPRETAÇÃO GEOLÓGICA DE DADOS GRANU-} LOMÉTRICOS Os trabalhos de interpretação geológica de dados granulométricos distribuem-se em duas vertentes principais: a primeira, e mais antiga, analisa e agrupa curvas acumulativas por meio de inflexões da distribuição granulométrica, quais sejam dados estatísticos referentes a diâmetro médio, desvio-padrão, assimetria e curtose. A segunda busca interpretar descritores numéricos da distribuição granulométrica, quais sejam, os parâmetros estatísticos.

Interpretação de Curvas Acumulativas Visher (1969) propõe, com base em ampla literatura prévia e na observação de resultados de mais de 2.000 amostras, que os modos fundamentais de transporte sedimentar (arraste, saltação e suspensão) acham-se registrados nas curvas acumulativas por meio de inflexões significativas.

Uma análise de mais de 1.500 amostras teria mostrado que a seleção, variação de tamanho e pontos de truncamento dessas populações podem permitir compreender a ação de correntes e ondas, proveniência e taxas de deposição dos sedimentos. Esta hipótese foi testada para mais de 500 amostras de ambientes marinhos modernos da costa americana, sobre cujos locais de coleta se reuniram observações sobre marés, ondas, modelos de transporte e geomorfologia do sítio deposicional.

Viard \& Breyer (1979), em estudo realizado em Platte River, afluente do Missouri, propõem-se a desenvolver as idéias de Visher (1969) no sentido de determinar condições hidráulicas, especialmente velocidades de tração, a partir das curvas de distribuição granulométrica, porém os resultados obtidos não foram conclusivos.

Essa linha de pesquisa não é retomada nos demais trabalhos de literatura consultada.

\section{Interpretação de Estatísticas}

Folk \& Ward (1957) realizaram estudo sobre sedimentos de uma barra fluvial constituída de areia e cascalho. Ao analisarem a relação entre a proporção de cascalho e modas de areia e cascalho verificaram 1) a fração cascalho tem tamanho e seleção essencialmente constantes e independentes da quantidade total de cascalho; isto indicaria que a granulometria do depósito é função da granulometria da área-fonte, sendo pouco afetada por fatores hidráulicos e força de corrente transportadora; e 2) acima de $5 \%$ de cascalho, não há mais correlação entre as proporções de cascalho e areia das amostras.

Estes autores estendem suas conclusões no sentido de que variações de curtose e assimetria a partir de certos valores normais podem ser indicativas de bimodalidade, enquanto que valores extremos de curtose podem ser interpretados no sentido de que o sedimento considerado guarda características de uma fase prévia, cujo meio foi mais eficiente em promover seleção que o meio em que veio a ser depositado.

Shepard \& Young (1961) contestam o valor da assimetria como parâmetro interpretativo de ambiente. Folk (1962) e Duane (1964) contestam essa conclusão e atribuem o insucesso dos primeiros autores ao método analítico, pois Shepard \& Young (op. cit.) realizaram análise em tubo de sedimentação, o que levaria a valores de assimetria sistematicamente negativos. Duane ( $o p$. cit.) acredita que as distribuições granulométricas obtidas por tubo de sedimentação diferem das obtidas por peneiramento, não sendo válido comparar resultados dessas duas técnicas.

Duane (1964) realizou estudo em diversos ambientes da Carolina do Norte (EUA), voltado à interpretação da assimetria. Os cálculos foram feitos sedundo o método dos momentos e os resultados obtidos para algumas amostras foram comparados com os calculados por outras fórmulas. Considera que os sinais obtidos para assimetria por diferentes fórmulas são compatíveis e, portanto, os resultados de assimetria podem ser considerados reprodutíveis.

Uma análise detalhada, por ambientes de deposição, levou Duane (1964) a admitir que a assimetria é sensível ao ambiente. Com sinal negativo indicaria remoção seletiva (winnowing) contínua, característica de praias, zonas litorâneas e canais de entrada de marés (tidal inlets). Com sinal positivo caracterizaria zonas protegidas de deposição, como lagunas, bem como dunas de deposição eólica.

Hails (1967) estudou mais de 1.500 amostras na região costeira de Nova Gales do Sul (New South Wales) (Austrália), de ilhas barreiras, praias, dunas e planícies flúvio-deltaicas, em busca de um parâmetro que permitisse separar esses diversos ambientes. Mostrou que isso não poderia ser feito pelos diâmetros médios nem pela morfologia (arredondamento) dos grãos e, sim, pela assimetria.

Para Friedman (1967), as distribuições granulométricas têm significado genético e permitem distinguir com segurança sedimentos fluviais de praias. Para tanto sugere numerosas combinações gráficas entre parâmetros (por exemplo, assimetria $x$ desvio-padrão), que permitem separar populações de diferentes origens.

Cronan (1972) realizou estudo de sedimentos de superfície de fundo no Mar da Irlanda, entre a Ilha de Man e Cumberland, caracterizados por polimodalidade. Para esse autor, a interpretação de Duane (1964) - assimetria negatia indicaria erosão ou não deposição enquanto assimetria positiva indicaria deposição - não pode ser estendida a sedimentos fortemente polimodais. Assim, no caso do Mar da Irlanda, há uma deposição de sedimentos cada vez mais finos de oeste para leste, à medida que diminui a força das correntes de maré, de tal modo que os valores das estatísticas vão refletir as diferentes proporções de misturás de diferentes modas e não o regime deposicional, que é único.

Os trabalhos e os resultados até aqui mencionados de certa maneira podem ser filiados a uma linha que parte de Folk \& Ward (1957), e sua tônica é o reconhecimento de diferentes populações de sedimentos, ou seja, de diferentes processos de sedimentação, mediante estatísticas 
simples ou combinadas duas a duas, sempre de modo empírico. Dois fatores explicam as características granulométricas de cada população: a composição da área-fonte e o peso relativo dos processos de transporte (rolamento, saltação e suspensão) e deposição. Assimetria emerge como o fator geneticamente mais sensível, mostrado ainda por outros autores, como Chappell (1967) e Hails \& Hoyt (1969), que destacam algumas alterações nos valores das estatísticas, especialmente na cauda dos finos produzidos por pedogênese.

Contemporaneamente a Folk \& Ward, Passega (1957) procura estudar as relações entre textura dos sedimentos e processos de deposição pela mediana (M) - justamente o parâmetro que Folk \& Ward (1957) propõem abandonar e pelo primeiro percentil (C).

Passega justifica a escolha desses valores com as seguintes considerações: 1) seu objetivo é encontrar o modo de deposição e não descrever a distribuição granulométrica; 2) acredita, com base nos trabalhos de Doeglas (1968) e Van Andel \& Postma (1954), que a textura de um sedimento composto por frações finas e grossas seja função de dois fatores independentes; assim, descritores da curva total, como seleção e assimetria, não seriam adequados à inferência de processos deposicionais; e 3) considera que a fração grossa de um sedimento é mais representativa do agente deposicional que a fração fina. Isso levou-o a usar a mediana para delimitar a porção mais grossa de sedimento e, nessa subpopulação, o primeiro percentil seria representativo de um limite mínimo de máxima competência (pois há de admitir que o meio possa ter sido mais competente, sem que houvesse material de porte compatível disponível). A partir de estudo empírico das relações entre C e M, em diversos ambientes fluviais e costeiros, Passega (1957) propôs um gráfico de referência para o reconhecimento de diversos ambientes de sedimentação.

Finalmente, uma terceira tendência na interpretação geológica de parâmetros estatísticos é apontada por Salu (1964). Trata-se da análise multivariável discriminante, que este autor aplicou a 203 amostras de ambientes praial, eólico, marinho raso, deltáico e de correntes de turbidez.

Essas amostras foram analisadas e tiveram suas estatísticas calculadas segundo Folk \& Ward (1957), sendo adicionalmente definido um novo parâmetro denominado Índice Modal $\left(\mathrm{m}_{\phi}\right)$ :

$$
\mathrm{m}_{\phi}=1+\frac{\phi_{e}-\phi_{1}}{2_{1}}
$$

em que $\phi_{e}$ é o tamanho da moda mais fina; $\phi_{1}$, o tamanho da moda mais grosseira; e $\sigma_{1}$, o desvio-padrão.

Sahu (1964) verificou que os desvios-padrão dos parâmetros aumentavam progressivamente na sequêencia eólico praial-marinho raso-fluvial (deltaico)-correntes de turbidez. $\mathrm{O}$ desvio-padrão da assimetria mostrou grande recobrimento entre os diversos ambientes de deposição e esse parâmetro não foi então levado em conta na interpretação.

Diversas combinações dos desvios-padrões dos outros parâmetros levaram-no a concluir que a melhor separação entre os diferentes processos e ambientes de deposição poderia ser obtida num gráfico log-log de

$$
\sqrt{\sigma_{1}^{2}} \text { contra } \frac{\mathrm{SKg}}{\mathrm{SMz}} \cdot \mathrm{S} \cdot \sqrt{\sigma_{1}^{-2}}
$$

sendo $\sqrt{\sigma_{1}^{-2}}$ o desvio padrão da variância; SKg, o desvio-padrão da curtose, $\mathrm{eSMz}$, o desvio-padrão do diâmetro médio.
"Se as estatísticas da amostra estão distribuídas normalmente em torno dos valores médios do mecanismo ou ambiente deposicional correspondente, então uma análise discriminante multivariável é o melhor método de discriminação. Podem-se estabelecer diversas funções discriminantes com limites característicos para o mecanismo ou ambiente de deposição, que permitem distinguir entre mecanismos e ambientes adjacentes que tenham condições de energia muito próximas. $O$ teste ' $t$ ' destas funções discriminantes pode ser usado para determinar o mecanismo ou ambiente de amostras cujo mecanismo ou ambiente de deposição seja incerto" (Sahu 1964, p. 81-82).

Em relação aos resultados obtidos, Sahu $(1964$, p. 79$)$ destaca que as funções discriminantes por ele apresentadas foram as melhores possiveis a partir das amostras usadas e podem não ser eficientes em outras situações: "À medida que maior número de amostras se torne disponível e mais localidades para cada ambiente sejam incluídas, espera-se que as funções discriminantes melhorem e passem a ter aplicação mundial".

Como os demais trabalhos referidos, também este propõe um caminho que busca ser universalmente válido. Vistos em perspectiva, porém, e ainda levando em conta as limitações abordadas anteriormente, pode-se dizer que todos são interessantes mas parciais e sua validade, regional ou local. "Apesar do recente progresso em nossa compreensão das implicações genéticas das distribuições de freqüência (granulométrica), a correlação entre ambiente deposicional e parâmetros texturais não é uma panacéia. Tanto é perigoso subestimá-la como superestimá-la. Distribuições multimodais, especialmente as de areias grossas, podem ter parâmetros texturais imprevisíveis; areias praiais de áreas em que o fornecimento de sedimentos excede a energia podem ter uma cauda fina, de tal modo a se assemelharem às fluviais" (Friedman 1967).

\section{INTERPRETAÇÃO DE DADOS GRANULOMÉTRICOS EM QUATRO SETORES DA COSTA BRASILEIRA Embo-} ra haja numerosos trabalhos brasileiros envolvendo análises e interpretações de dados granulométricos, esta exposição ficará limitada a casos estudados por nós, cujos dados estavam mais facilmente acessíveis. Além disso, foram abordados só os dados obtidos sob mesmas condições laboratoriais. Compreendem eles duas baías, as de Santos (SP) e Sepetiba (RJ), e os estuários do Potengi (RN) e do Itajaí-Açu (SC).

Interpretações parciais sobre os casos de Santos, Sepetiba e Potengi foram apresentados por Fúlfaro \& Ponçano (1976), Ponçano et al. (1976), Fúlfaro et al. (1978) e Ponçano \& Fúlfaro (1978). Nesses trabalhos são feitas tentativas empíricas de correlação entre as estatísticas granulométricas, calculadas segundo as fórmulas de Folk \& Ward (1957), e certos fatores dos ambientes sedimentares envolvidos. Resumidamente, os resultados de diâmetros médios são empregados na definição das áreas de influência de domínios fluviais e marinhos, de áreas-fontes localizadas (pontões, dunas) e à energia do meio transportador. $\mathrm{O}$ grau de seleção é relacionado a fatores gerais, como, por exemplo, ao retrabalhamento de depósitos reliquiares da plataforma, ou locais, como retrabalhamento de depósitos de dunas. Em linhas gerais, o grau de seleção nessas interpretações parece refletir mais características prévias que as condições que prevaleceram durante a sedimentação nos locais amostrados. A distribuição dos valores 
de assimetria, por sua vez, poderia ser indicativa da atuação de correntes de fundo. Nos locais de atuação dessas correntes, os finos seriam removidos, resultando, então, assimetrias negativas. No caso da curtose, considerou-se que as distribuições leptocúrticas poderiam indicar remoção de uma fração dos sedimentos por meio de correntes de fundo enquanto as distribuições platicúrticas poderiam indicar mistura de populações diferentes.

Estas interpretações são semelhantes àquelas desenvolvidas por alguns autores e já mencionadas. Entretanto, considerando que as fórmulas usadas foram as de Folk \& Ward (1957) e que eles acharam uma relação definida entre os parâmetros calculados para uma população granulométrica no intervalo $-3 \phi$ a $+3 \phi$, pode-se inicialmente perguntar se a mesma relação se mantém para as amostras dos casos aqui considerados, que abrangem o intervalo de $0 \phi$ a $+8 \phi$. Ademais, considerando o uso interpretativo dessas estatísticas, apresenta-se-nos, aparentemente, um paradoxo: se houver uma relação definida entre os valores dessas estatísticas, qual o alcance de sua interpretação?

Para tentar responder a essas questões, compusemos as populações dos sedimentos de superfície de fundo das baías de Santos e Sepetiba, e dos estuários de Santos e Itajaí-Açu (nestes dois últimos casos incluindo pequeno setor da plataforma adjacente às desembocaduras dos estuários), representadas nos histogramas das figuras 1-A, 1-B, 1-C e 1-D. Obtivemos, então, um conjunto de 588 amostras, cuja distribuição, mostrada no histograma da figura 1-E, caracteriza bastante bem o intervalo de $0 \phi$ a $8 \phi$.

Procuramos então iniciar nossa análise pela comparação da primeira com as demais estatísticas, já que o diâmetro médio se constitui numa medida cujo significado físico pode ser apreendido de modo relativamente simples. Construímos então os diagramas binários apresentados nas figuras 2 a 6 . A fim de melhor captar as tendências esboçadas por simples plotagem, realizamos um alisamento (smoothing), que consiste, basicamente, em se traçar uma curva contínua através das medianas de grupos de pontos plotados; de modo experimental, por comparação visual de resultados gráficos, o alisamento foi realizado através de grupos de 10 pontos. Percebe-se que os gráficos das diferentes populações (Figs. 2 a 5) apresentam configurações que se delineiam de modo mais completo para o total das amostras (Fig. 6).

A distribuição do desvio-padrão (Fig. 6-A) mostra uma notável ruptura em torno de $+4 \phi$. Entre $0 \phi$, amostras distribuem-se em torno de um valor médio de desvio-padrão de 0,74 ; pode-se então dizer que todas as amostras desse intervalo granulométrico oscilam em torno de um grau de seleção que, pela escala de Folk \& Ward (1957), corresponde a moderadamente selecionado. Ainda nesse intervalo de $0 \phi$ a $+4 \phi$, pode-se notar que as oscilações do desvio-padrão em torno do valor de 0,74 são menores de $0 \phi$ a $+2 \phi$ a $+4 \phi$, o que sugere duas populações distintas.

Entre $+4 \phi$ e $+8 \phi$ pode-se traçar uma curva média, provavelmente definida por uma equação de segundo grau, inteiramente compreendida nos intervalos de valores pobre e muito pobremente selecionados de Folk \& Ward (1957). Neste caso nota-se que o desvio em torno da curva média diminui no intervalo granulométrico de $+7 \phi$ a $+8 \phi$.

Em relação à assimetria (Fig. 6-B), embora o diagrama de pontos seja sugestivo de uma certa ruptura próxima de $+4 \phi$, parece-nos que a tendência à definição de uma senóide pode ser estendida entre $+3 \phi$ e $+8 \phi$, conforme fica mais claro no diagrama submetido a alisamento.

Novamente parece definir-se uma população entre $0 \phi \mathrm{e}$ $+2 \phi$, caracterizada por valores oscilando em torno da linha de simetria.

No que se refere à curtose (Fig. 6-C), novamente julgamos reconhecer três populações. Uma no intervalo granulométrico de $0 \phi$ a $+2 \phi$, com valores de curtose em torno de 1,2 (mesocúrticos); outra no intervalo $+2 \phi$ a $+4,5 \phi$ com valores de curtose em torno de 1,5 (leptocúrticos); e uma terceira, de $4,5 \phi$ a $8 \phi$, com valores platicúrticos a mesocúrticos, segundo a escala de Folk \& Ward (1957).

Em relação ao conjunto das estatísticas, podemos então destacar que, para o universo analisado, é possível definir três conjuntos de amostras nos intervalos granulométricos aproximados de $0 \phi$ a $+2 \phi$, de $+2 \phi$ a $+4 \phi$ e de $+4 \phi$ a $+8 \phi$. $O$ primeiro desses intervalos caracteriza-se por pequenas oscilações dos valores de desvio-padrão, assimetria e curtose em torno de um valor médio (nulo, no caso da assimetria). O segundo guarda certa semelhança com o primeiro, caracterizando-se entretanto por maiores oscilações em torno do valor médio; o valor médio da curtose para este caso é maior que no primeiro.

$O$ intervalo de $+4 \phi$ a $+8 \phi$ caracteriza-se por uma relação mais complexa entre as estatísticas, embora bem definida nos diagramas binários.

Os resultados acima expostos complementam os obtidos por Folk \& Ward (1957) e nos levam a afirmar que as relações entre parâmetros granulométricos são válidas para dados intervalos granulométricos. Entretanto essas relações não parecem ser contínuas e passíveis de expressão unicamente pela equação do helicóide.

Adicionalmente, achamos oportuno retomar a questão assim proposta por Folk \& Ward (1957, p. 14): "Uma escala verbal de seleção realmente significativa será desenvolvida somente quando a tendência geral da relação entre tamanho e seleção for construída para um grande número de ambientes. Somente então será possível dizer, por exemplo, que um sedimento tem um desvio-padrão $0,25 \phi$ mais baixo que o sedimento médio correspondente àquele diâmetro médio".

Esse raciocínio parece-nos válido, e provavelmente seja um caminho a ser pesquisado e estabelecido para o futuro. Entretanto julgamos que deva ser aplicado também às demais estatísticas, ou seja, uma vez definida uma relação entre diâmetro médio, desvio-padrão. assimetria e curtose, não nos parece viável usar uma escala absoluta para nenhum caso.

Tendo assim proposto uma primeira abordagem para a solução do paradoxo anteriormente mencionado, podemo-nos perguntar a respeito do significado das três populações acima definidas.

A descontinuidade mais notável, em torno de $+4 \phi$, assinala não só a separação entre areias e siltes como também a mudança do método granulométrico. Enquanto para areias se procede a peneiramento, estabelecendo-se portanto uma referência física para a separação das classes granulométricas, siltes e argilas são divididos segundo a lei de Stokes. Entretanto, dada a abrupta passagem dos valores de desvio-padrão no limite de $+4 \phi$ de 0,7 para 2,4 , há margem para se considerar que a passagem de areias para siltes corresponda a uma mudança dinâmica, possivelmente um limite natural entre transportes de preferência por arraste e por suspensão. 

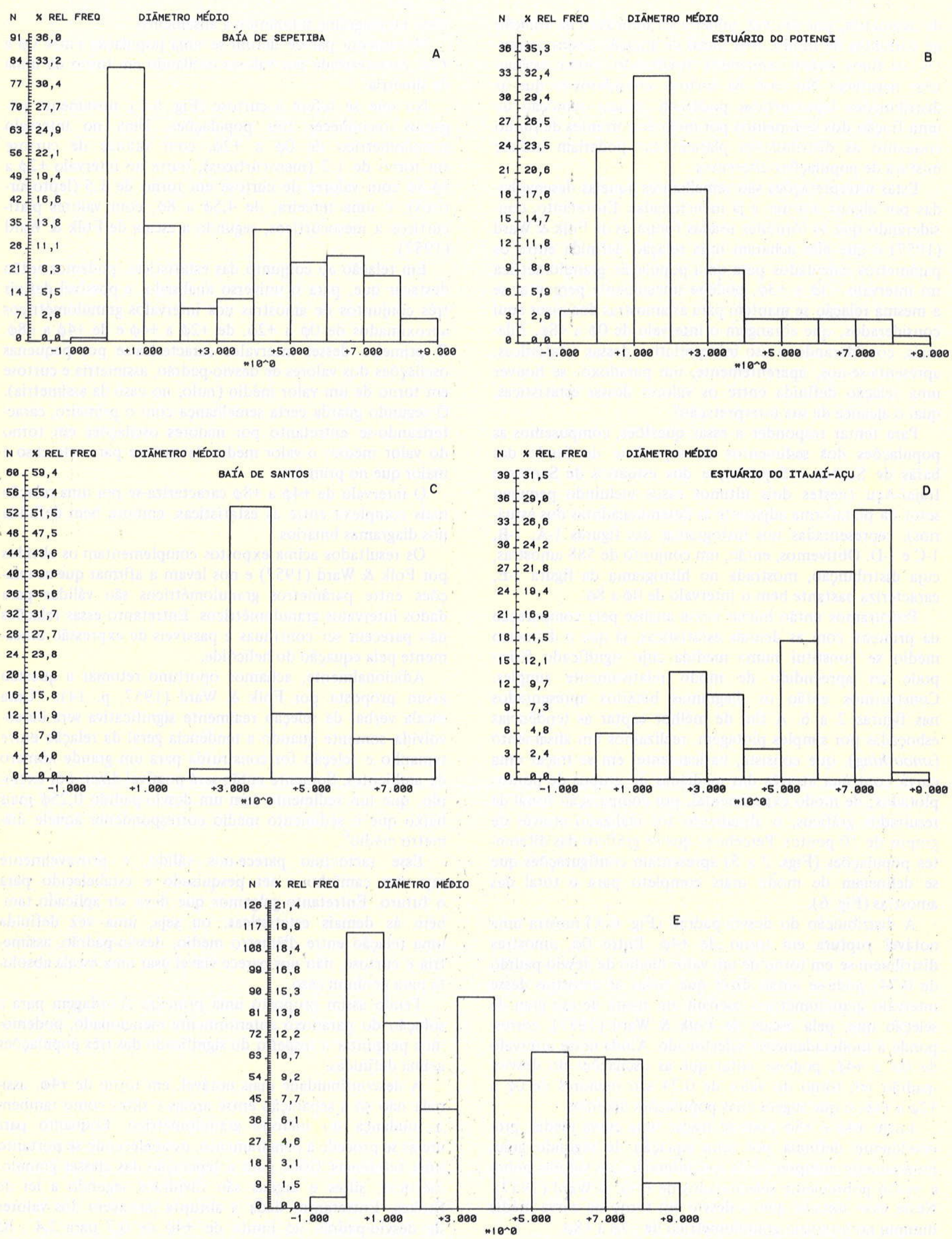

Figura 1 - Freqüência de amostras por intervalo granulométrico para: A- Baía de Sepetiba (253 amostras); B- estuário do Potengi (110) amostras; C- Baia de Santos (101 amostras); D- estuário do Itajai-Açu (124 amostras); e E- para o total de 588 amostras 


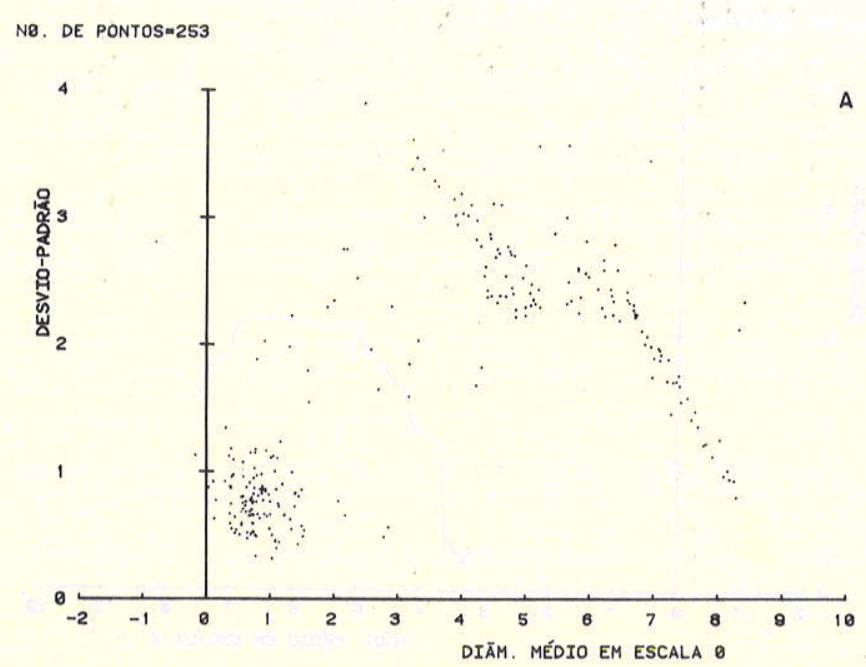

No. DE PONTOS=253

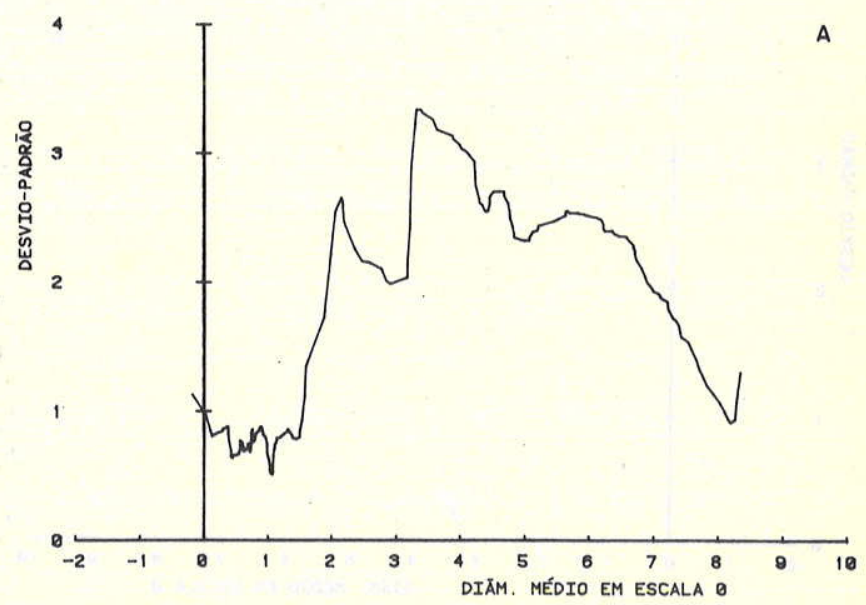

NQ. DE PONTOS $=253$

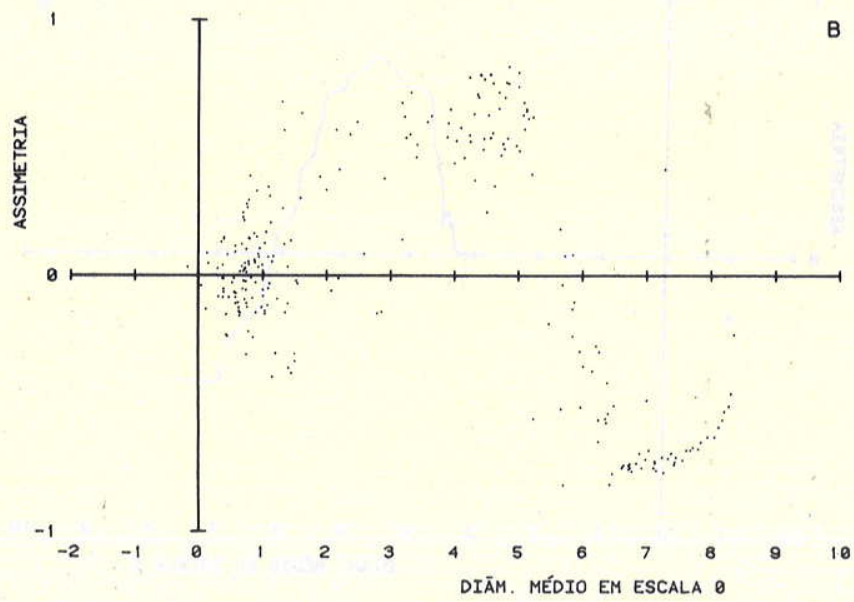

N9. DE PONTOS=253

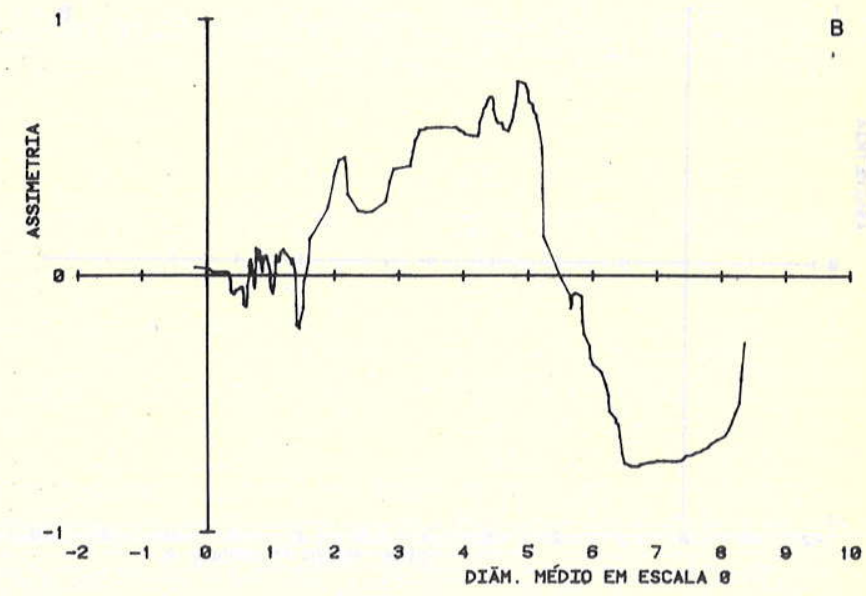

Ne. DE PONTOS=253

NB. DE PONTOS=253
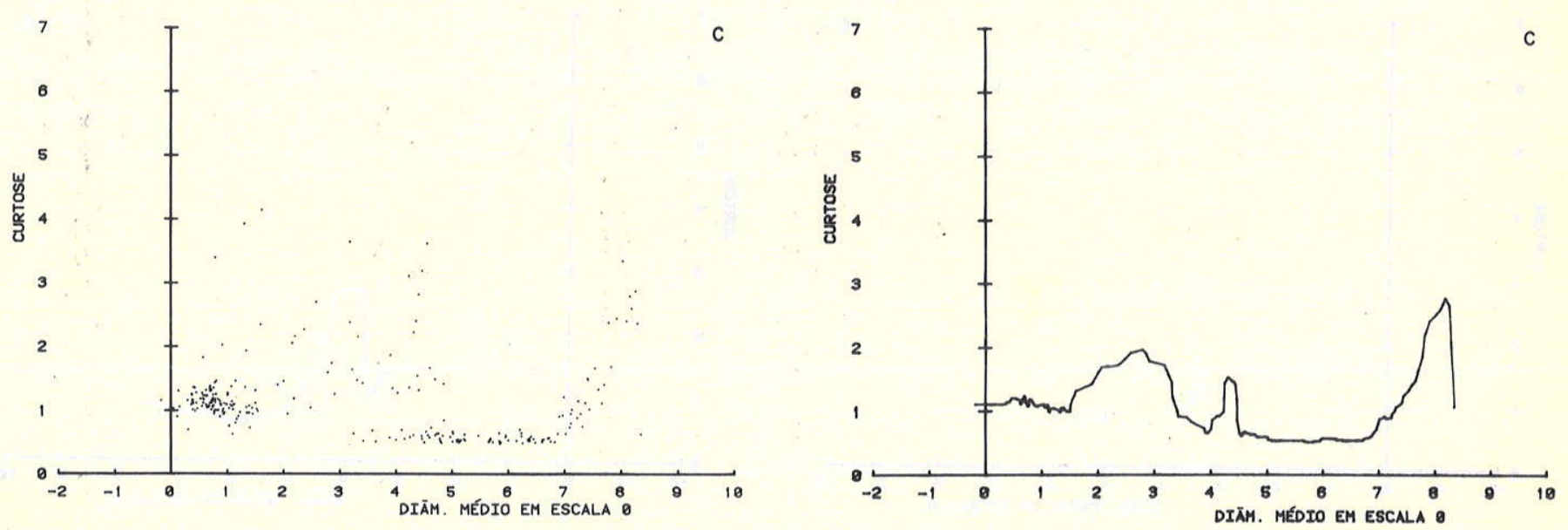

Figura.2 - Diagramas binários da Baía de Sepetiba, por simples plotagem de pontos e com alisamento para: A- diâmetro médio $\mathrm{x}$ desvio-padrão; $\mathbf{B}$ - diâmetro médio x assimetria; $\mathrm{e} \quad \mathrm{C}$ - diâmetro médio $\mathrm{x}$ curtose 


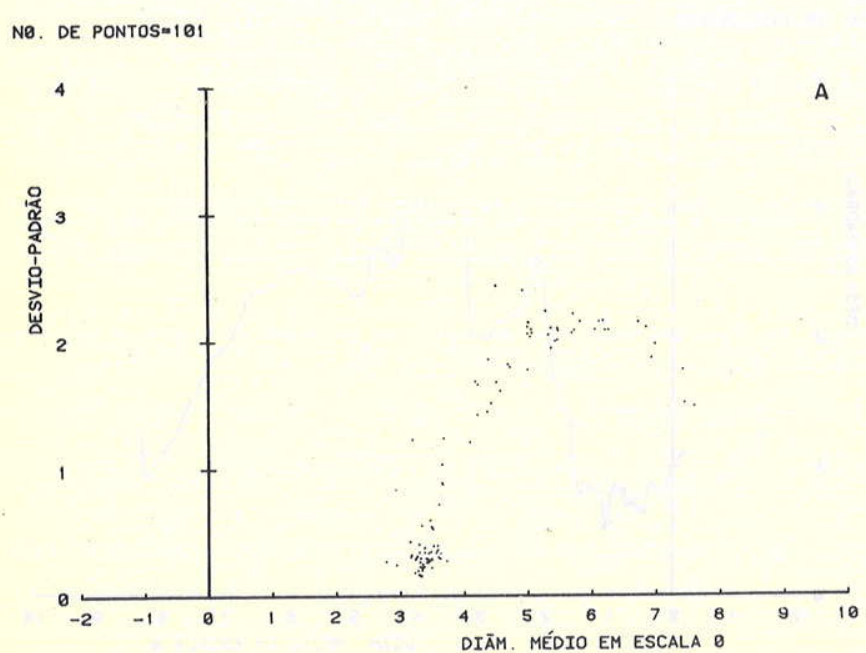

Ni. DE PONTOS=181

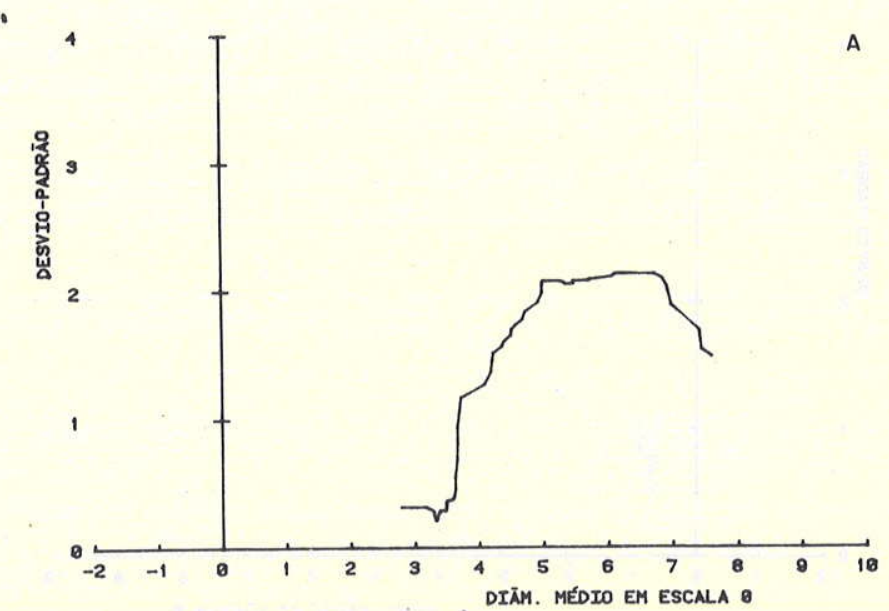

Ne. DE PONTOS=101

N. DE PONTOS=101
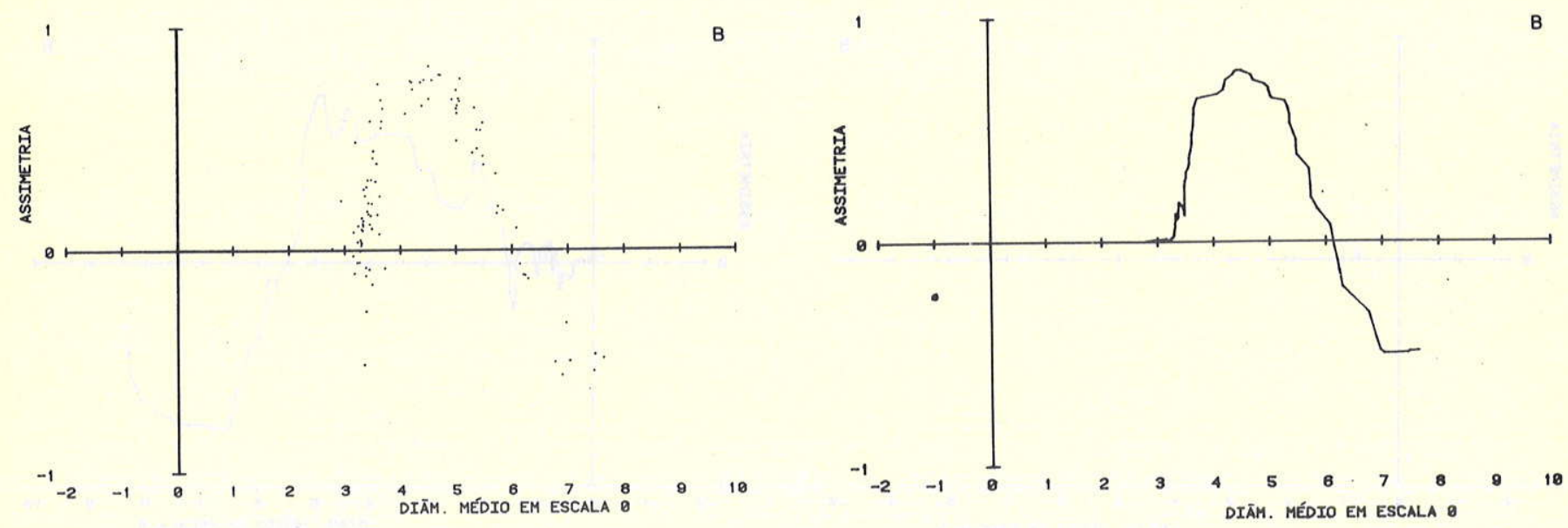

NQ. DE PONTOS=101

Ne. DE PONTOS=101
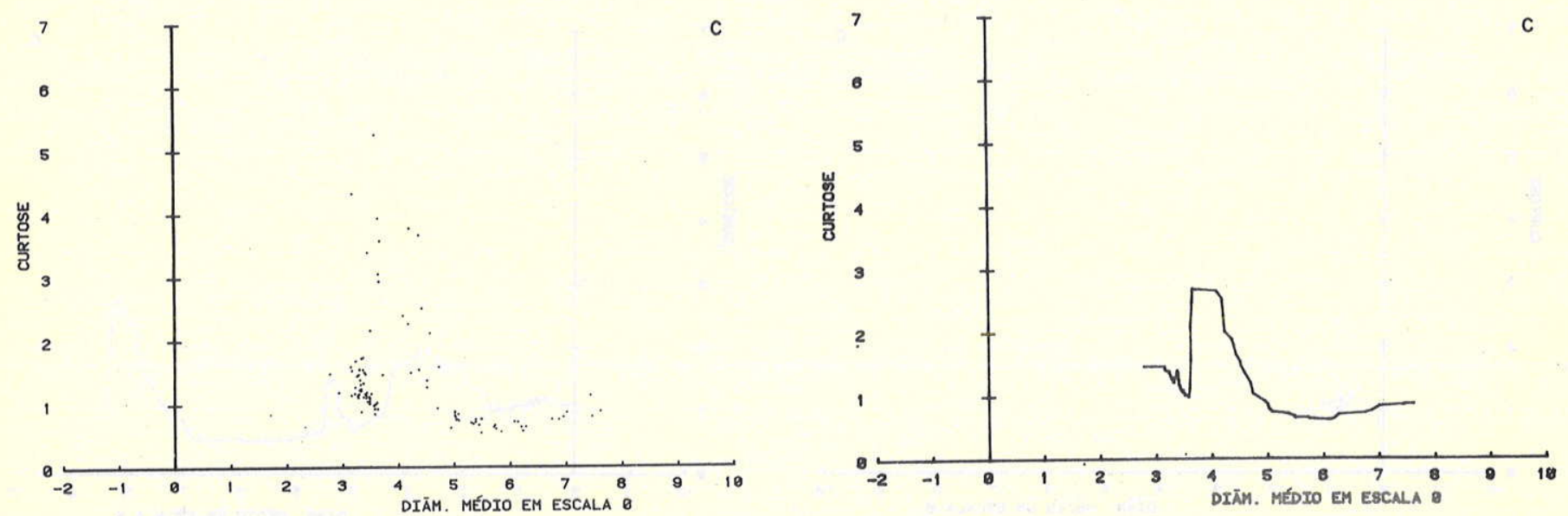

Figura 3 - Diagramas binários da Baía de Santos, por simples plotagem de pontos e com alisamento para: A- diâmetro médio $\mathrm{x}$ desvio-padrão; $\mathbf{B}$ - diâmetro médio $\mathrm{x}$ assimetria; $\mathrm{e}$ C- diâmetro médio $x$ curtose 
NO. DE PONTOS $=110$

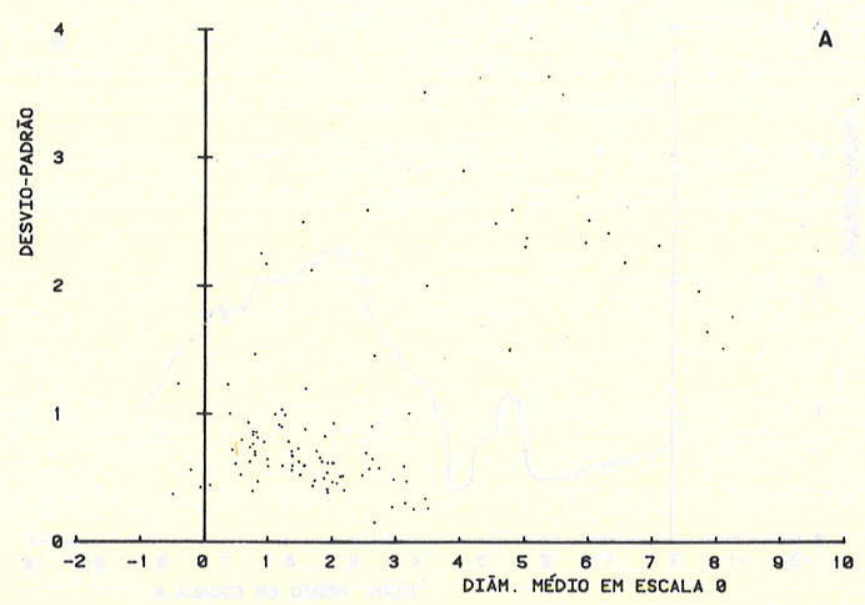

Ne. DE PONTOS=110

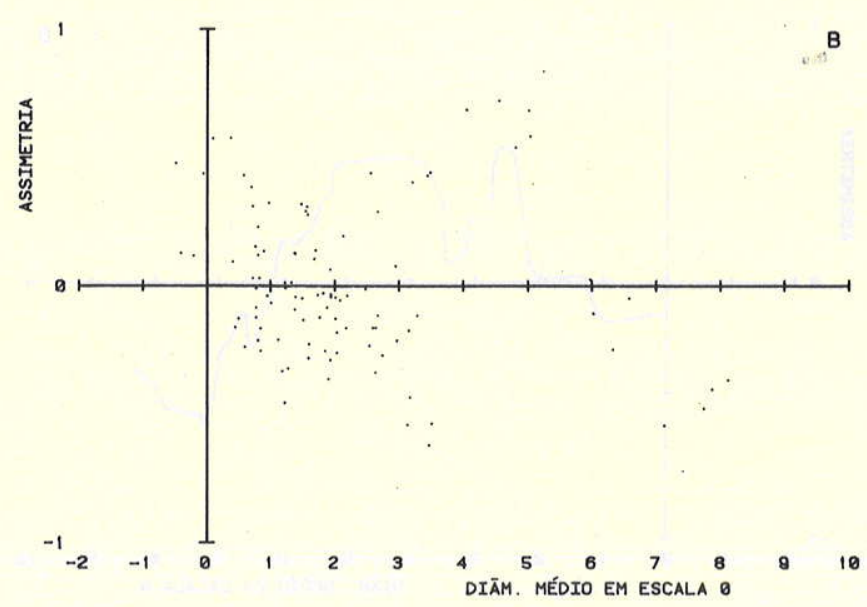

Ne. DE PONTOS=110

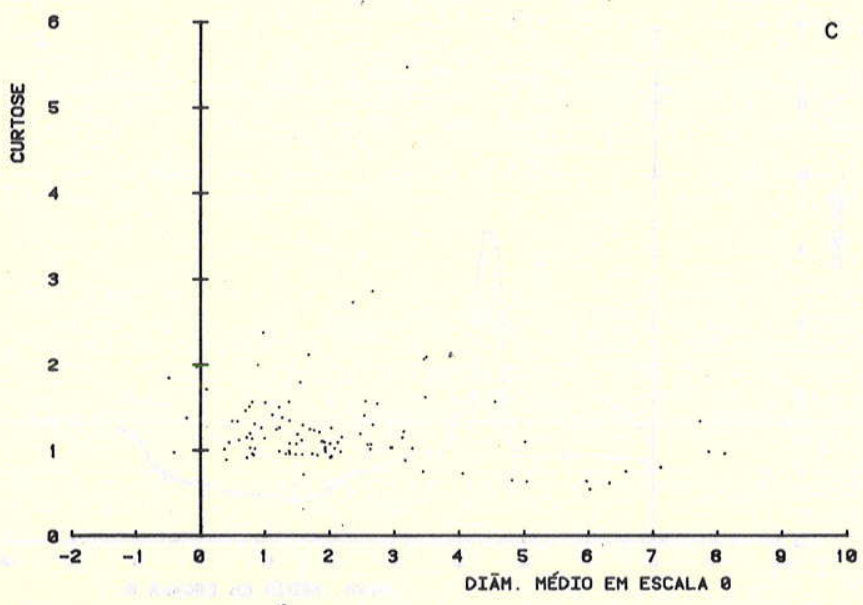

NB. DE PONTOS-118

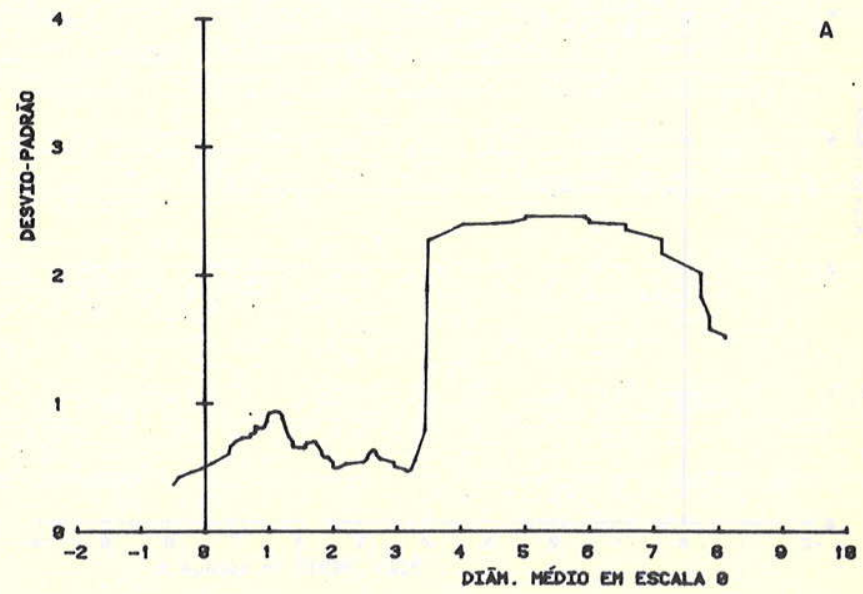

Ne. DE PONTOS=1 10

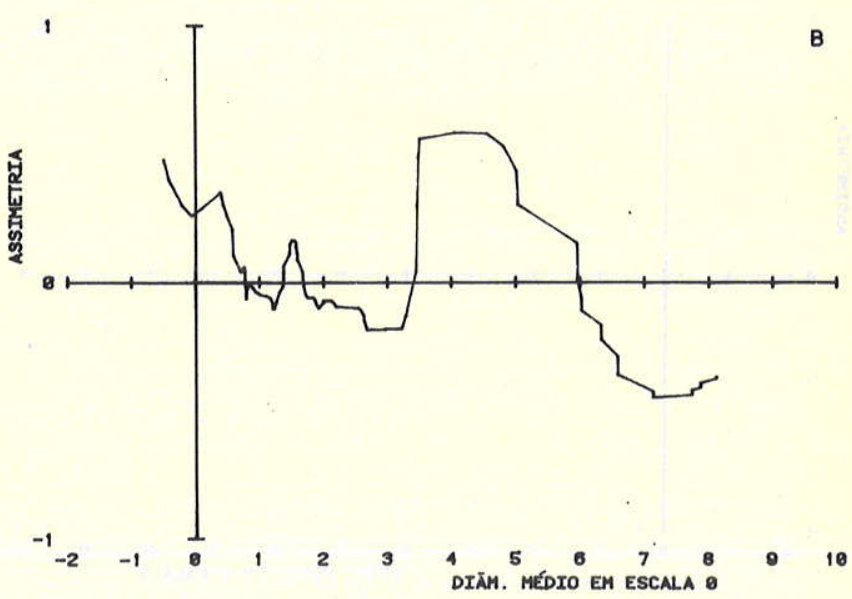

Ne. DE PONTOS=110

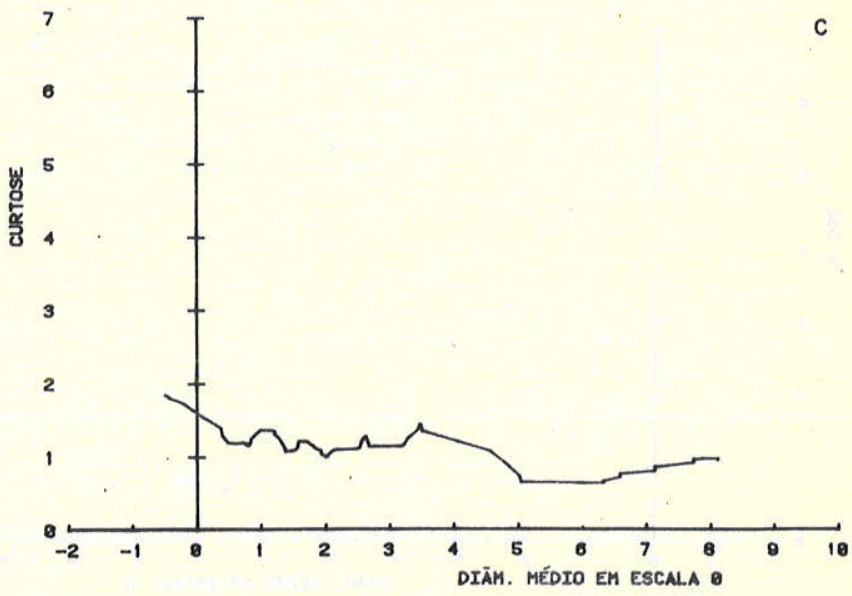

Figura 4 - Diagramas binários do estuário de Potengi, por simples plotagem de pontos e com alisamento para: A- diâmetro médio $\mathrm{x}$ desvio-padrão, $\mathrm{B}$ - diâmetro médio $\mathrm{x}$ assimetria; $\boldsymbol{e} \mathrm{C}$ - diâmetro médio $x$ curtose 
NO. DE PONTOS=124

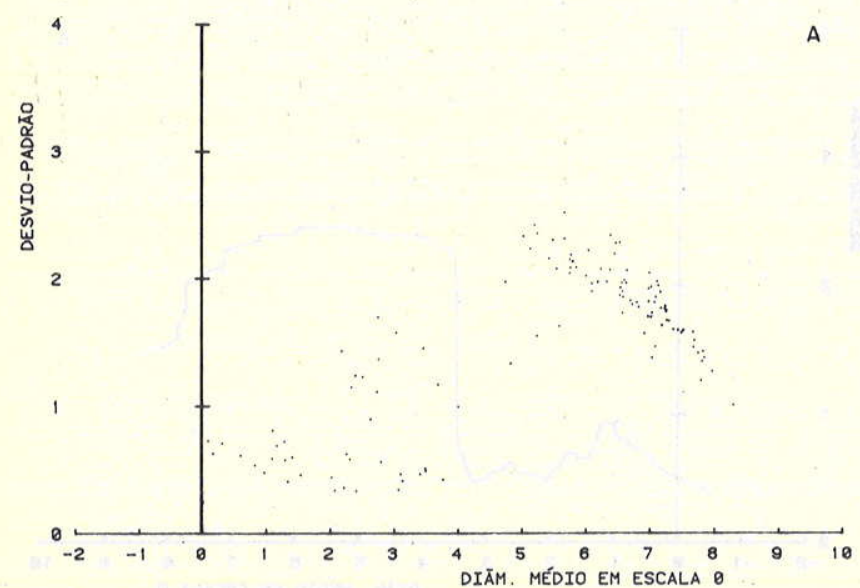

NO. DE PONTOS=124

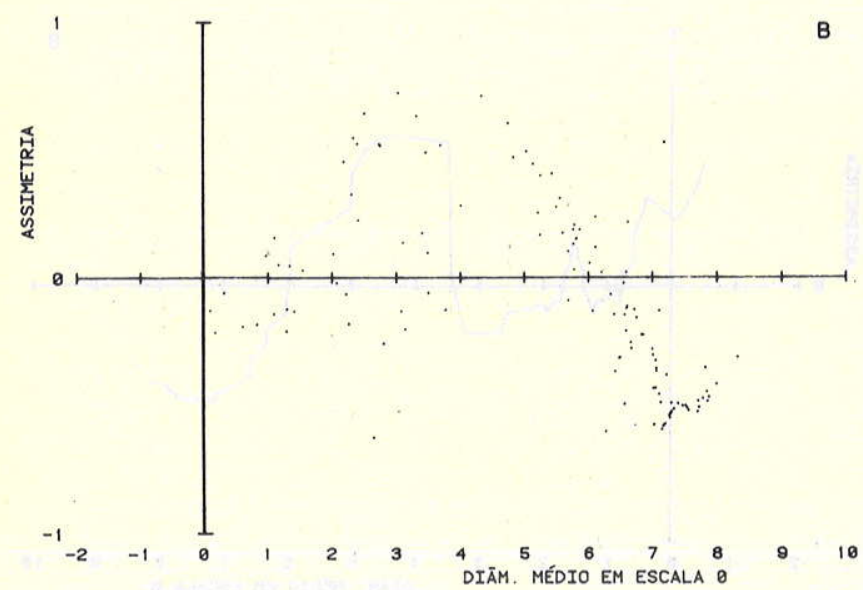

NQ. DE PONTOS=124

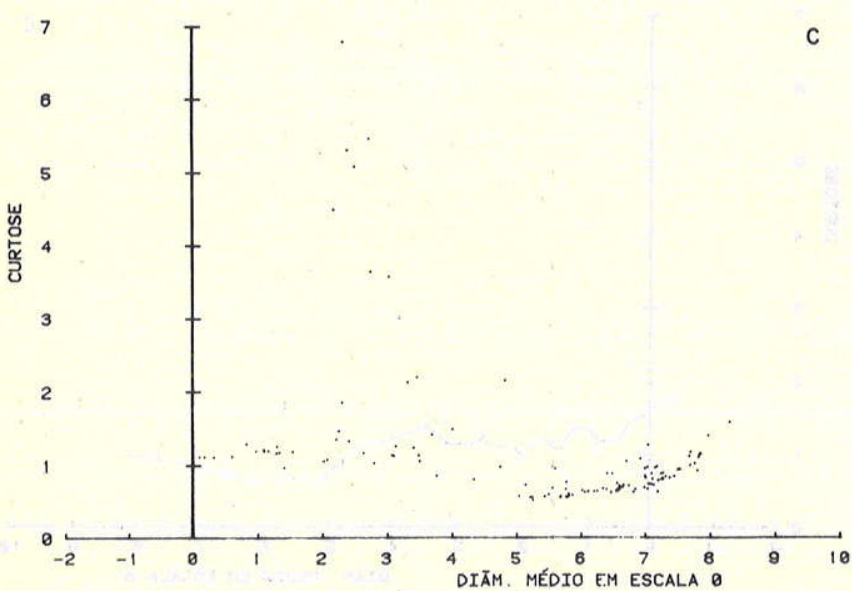

NO. DE PONTOS=124

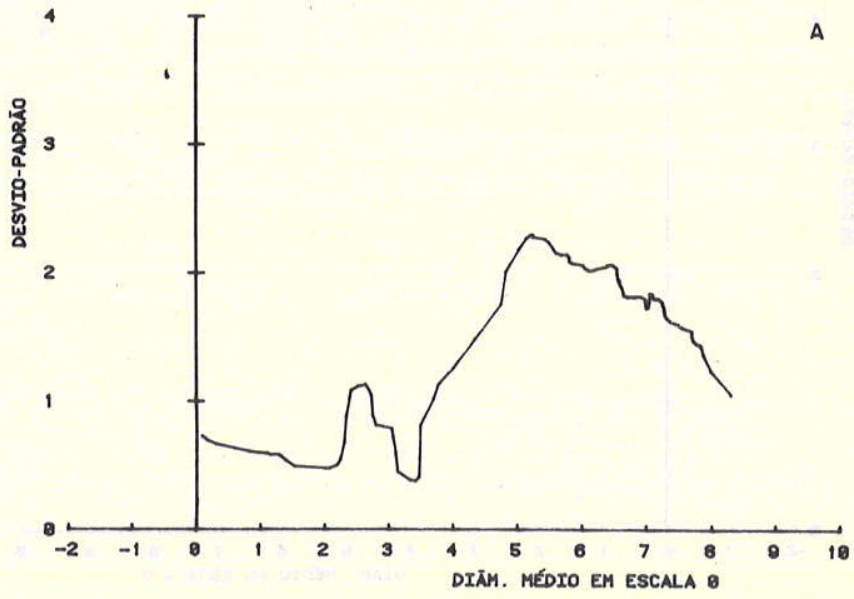

Ne. DE PONTOS=124

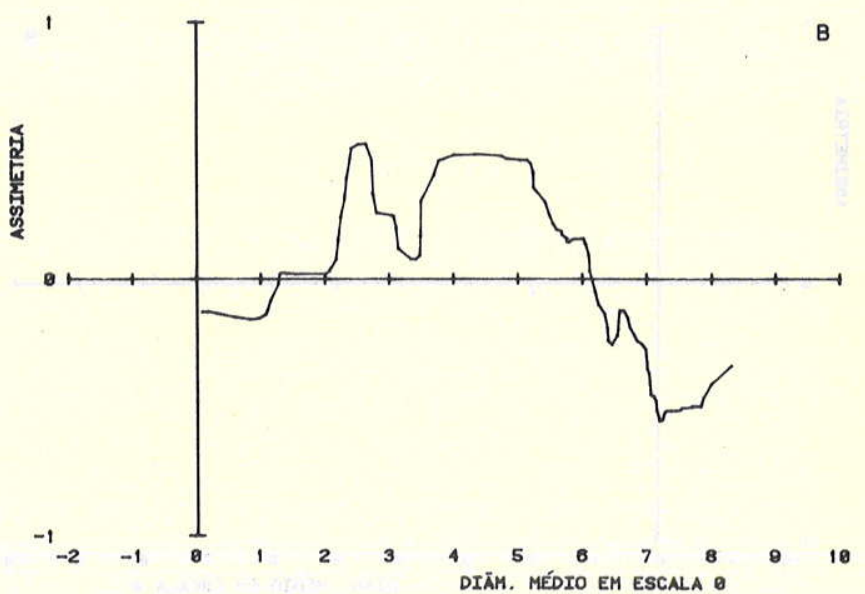

Nอ. DE PONTOS=124

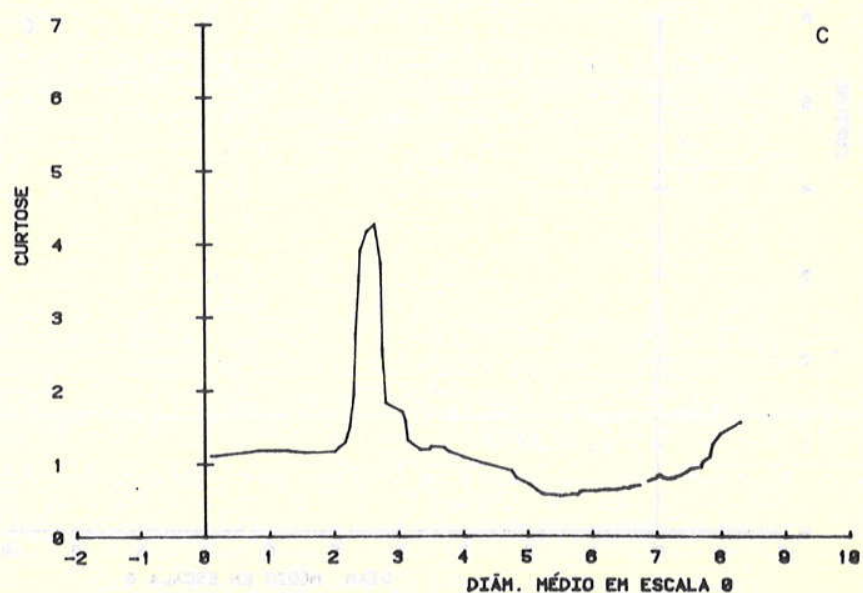

Figura 5 - Diagramas binários do estuário de Itajai-Açu, por simples plotagem de pontos e com alisamento para: A-diâmetro médio $\mathrm{x}$ desvio-padrão; $\mathrm{B}$ - diâmetro médio $\mathrm{x}$ assimetria; $\boldsymbol{e} \mathbf{C}$ - diâmetro médio $\mathrm{x}$ curtose 


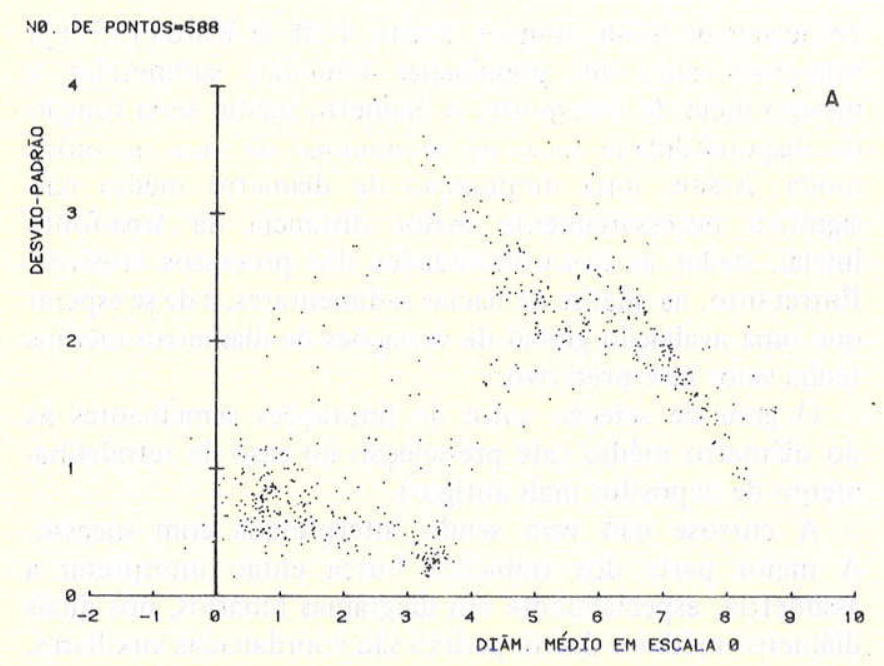

Nล. DE PONTOS=588

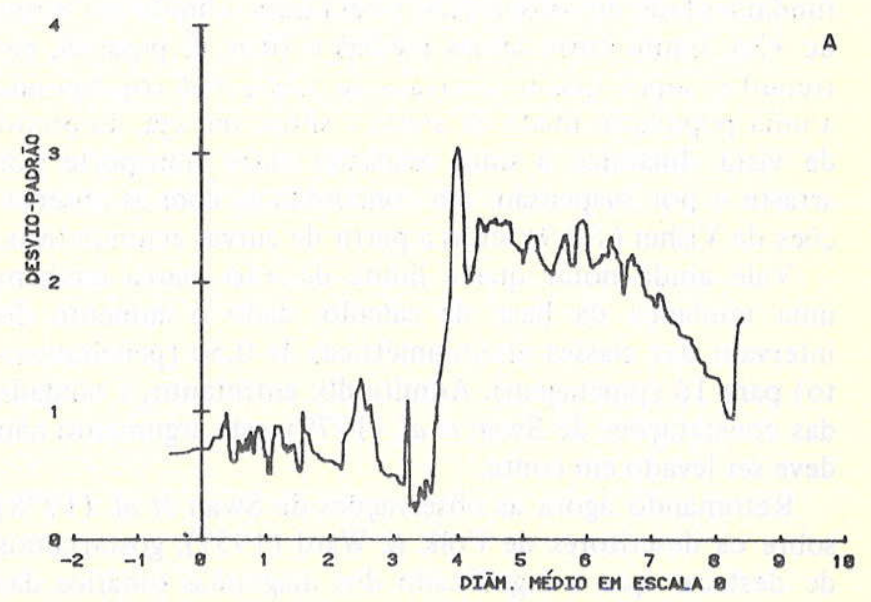

NQ. DE PONTOS $=588$

Nอ. DE PONTOS $=588$
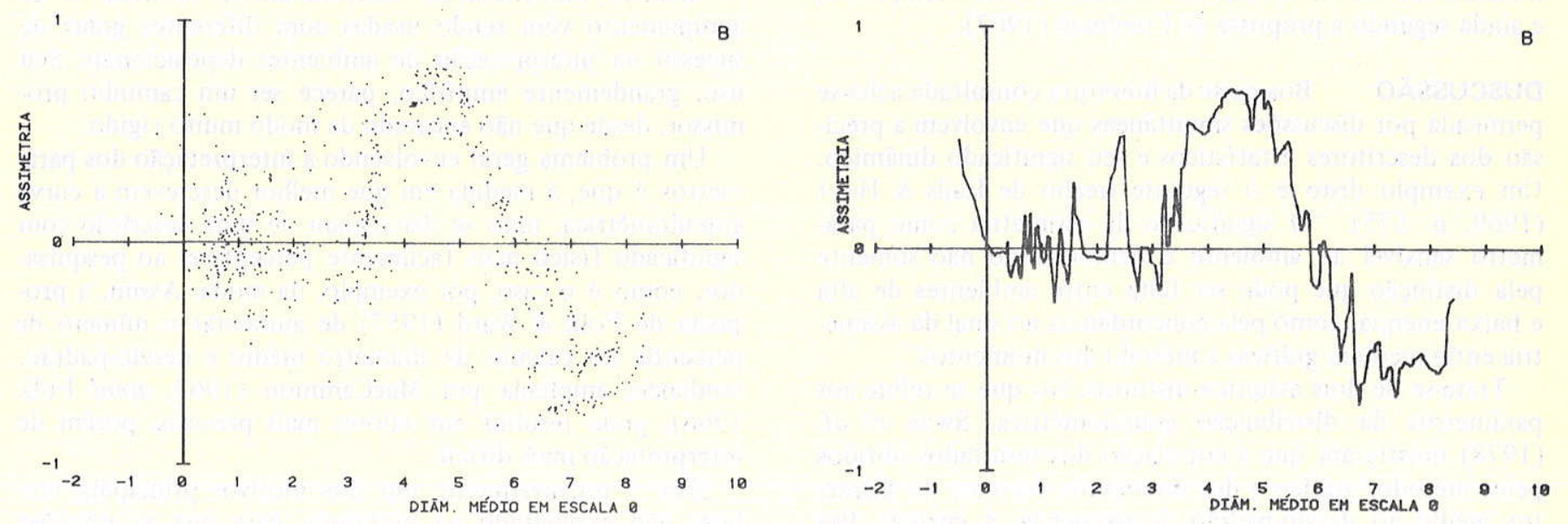

Ne. DE PONTOS-588

ํ. DE PONTOS $=588$
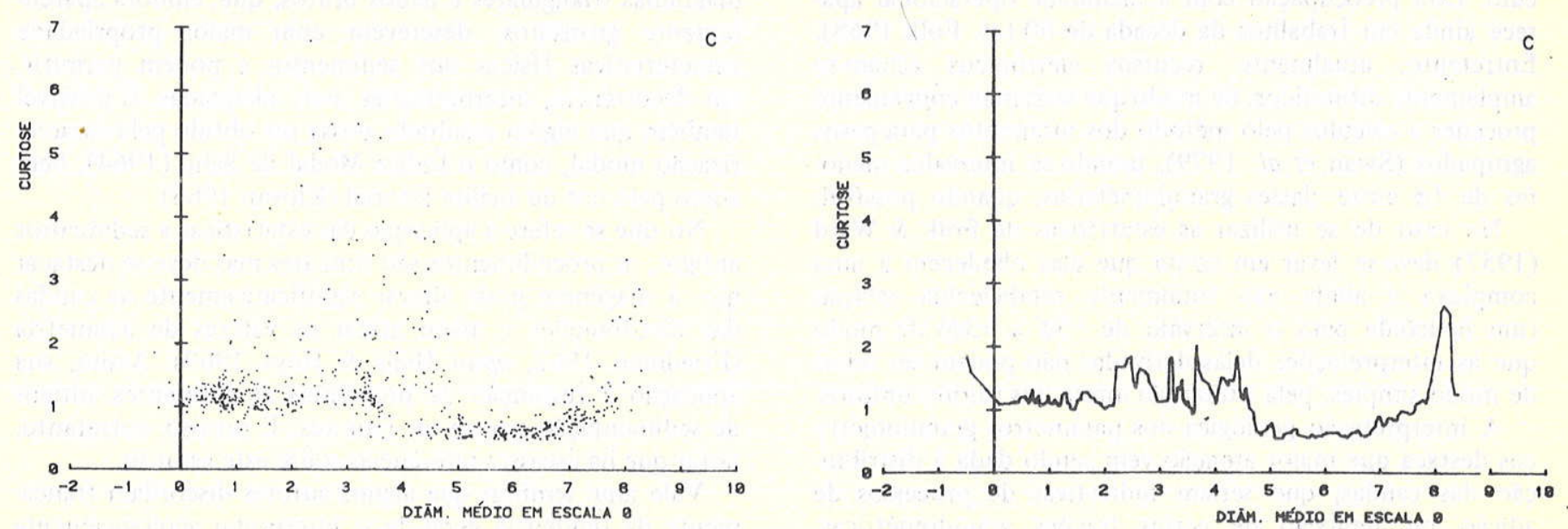

Figura 6 - Diagramas binários do total das amostras, por simples plotagem de pontos e com alisamento para: A- diâmetro médio $\mathrm{x}$ desvio-padrão; $\mathbf{B}$ - diâmetro médio $\mathrm{x}$ assimetria; $\boldsymbol{e}$ C-diâmetro médio $\mathrm{x}$ curtose 
Não temos elementos para avançar qualquer explicação fundamentada em observação direta para o limite em torno de $+2 \phi$, limite entre areias médias e finas. É possível, entretanto, supor que o intervalo de $+2 \phi$ a $+4 \phi$ corrresponda a uma população mista de areias e siltes, ou seja, do ponto de vista dinâmico a uma oscilação entre transporte por arraste e por suspensão, em concordância com as observações de Visher (1969) feitas a partir de curvas acumulativas.

Vale ainda notar que o limite de $+4 \phi$ marca também uma mudança da base de cálculo, dado o aumento do intervalo das classes granulométricas de $0,5 \phi$ (peneiramento) para $1 \phi$ (pipetagem). Admitindo, entretanto, a validade das constatações de Swan et al. (1979), este argumento não deve ser levado em conta.

Retomando agora as observações de Swan et al. (1978) sobre os descritores de Folk \& Ward (1957), gostaríamos de destacar que o significado dos diagramas binários das figuras 4,5 e 6 deverá decrescer no sentido diâmetro médio $x$ desvio-padrão, diâmetro médio $x$ assimetria, diâmetro médio $x$ curtose.

Levando em conta a complexidade das questões levantadas, não nos parece oportuno avançar essas considerações por meio da combinação de valores de desvio-padrão, assimetria e curtose entre si, como fizeram Folk \& Ward (1957) e ainda segundo a proposta de Friedman (1967).

DUSCUSSÃo Boa parte da literatura consultada acha-se permeada por discussões simultâneas que envolvem a precisão dos descritores estatísticos e seu significado dinâmico. Um exemplo disto é o seguinte trecho de Hails \& Hoyt (1969, p. 575): "O significado da assimetria como parâmetro sensível ao ambiente é demonstrado não somente pela distinção que pode ser feita entre ambientes de alta e baixa energia, como pela concordância no sinal da assimetria entre medidas gráficas e método dos momentos".

Trata-se de dois assuntos distintos. No que se refere aos parâmetros da distribuição granulométrica, Swan et al. (1978) mostraram que a correlação dos resultados obtidos pelos métodos gráfico e dos momentos decresce do diâmetro médio ao desvio-padrão, à assimetria, à curtose. Em decorrência, pode-se discutir resultados dos dois primeiros parâmetros sem levar em conta o método de cálculo, diversamente dos dois restantes.

As fórmulas de Folk \& Ward (1957) são ainda amplamente utilizadas por oferecerem maior facilidade de cálculo. Esta preocupação com a facilidade operacional aparece ainda em trabalhos da década de 60 (cf. Folk 1968). Entretanto, atualmente, recursos eletrônicos acham-se amplamente difundidos, de modo que seria mais conveniente proceder a cálculos pelo método dos momentos para pesos agrupados (Swan et al. 1979), usando-se intervalos menores de $1 \phi$ entre classes granulométricas, quando possível.

No caso de se utilizar as estatísticas de Folk \& Ward (1957) deve-se levar em conta que elas obedecem a uma complexa e ainda não totalmente estabelecida relação (um helicóide para o intervalo de $-3 \phi$ a $+3 \phi$ ) de modo que as interpretações delas derivadas não podem ser feitas de modo simples, pela utilização direta dos valores obtidos.

A interpretação geológica dos parâmetros granulométricos destaca que maior atenção vem sendo dada à distribuição das caudas, que seriam indicativas de processos de adição ou remoção de certas frações granulométricas. Diâmetro médio e desvio-padrão envolvem as noções de distâncias da área-fonte e grau de seleção e não podem ser enfocadas de modo simples. Assim, Folk \& Ward (1957)já sugeriram que, em populações bimodais submetidas a mesmo meio de transporte, o diâmetro médio seria função da disponibilidade local de sedimentos de uma ou outra moda. Assim, uma diminuição de diâmetro médio não significa necessariamente maior distância da área-fonte inicial, dadas as descontinuidades dos processos erosivos. Entretanto, na análise de bacias sedimentares, é de se esperar que uma avaliação global de variações de diâmetros médios tenha valor interpretativo.

$\mathrm{O}$ grau de seleção sofre de limitações semelhantes às do diâmetro médio (até pré-seleção no caso de retrabalhamento de depósitos mais antigos).

A curtose não vem sendo interpretada com sucesso. A maior parte dos trabalhos busca então interpretar a assimetria, especialmente em diagramas binários, nos quais diâmetro médio e desvio-padrão são coordenadas auxiliares. Até o momento, parece que a assimetria tem sido usada com êxito na distinção de ambientes em que predomina deposição (assimetria positiva) daqueles caracterizados por remoção seletiva (assimetria negativa). Friedman (1967) busca mostrar essas variações de assimetria relacionadas a processos de transporte em suspensão, saltação e arraste.

Análises multivariáveis discriminantes, fatoriais e de agrupamento vêm sendo usadas com diferentes graus de sucesso na interpretação de ambientes deposicionais. Seu uso, grandemente empírico, parece ser um caminho promissor, desde que não encarado de modo muito rígido.

Um problema geral envolvendo a interpretação dos parâmetros é que, á medida em que melhor descrevem a curva granulométrica, mais se distanciam de uma descrição com significado físico mais facilmente perceptível ao pesquisador, como é o caso, por exemplo, da moda. Assim, a proposta de Folk \& Ward (1957) de aumentar o número de percentis no cálculo de diâmetro médio e desvio-padrão, tendência ampliada por MacCammon (1962, apud Folk 1966), pode resultar em valores mais precisos, porém de interpretação mais difícil.

Esse é provavelmente um dos motivos principais, embora não explicitado na literatura, para que as atenções se tenham fixado de preferência na assimetria, já que esta, em última análise, busca descrever uma relação entre frações mais finas e mais grossas.

Para contornar esses problemas, talvez o diagrama de Passega (1957) possa ser mais bem explorado, bem como diagramas triangulares e dados brutos, que, embora aparentemente grosseiros, descrevem com maior propriedade características físicas dos sedimentos e podem permitir, em decorrência, interpretações mais adequadas. É possível também que algum resultado possa ser obtido pela caracterização modal, como o Índice Modal de Sahu (1964), bem como pelo uso de análise fatorial (Klovan 1966).

No que se refere à aplicação das estatísticas a sedimentos antigos, os procedimentos são similares mas deve-se destacar que a diagênese pode alterar significativamente as caudas das distribuições e assim afetar os valores de assimetria (Friedman 1962, apud Hails \& Hoyt 1969). Assim, sua aplicação à resolução de problemas de ambientes antigos de sedimentação parece ser limitada. É preciso, entretanto, notar que há escassas referências sobre este assunto.

Vale aqui lembrar que alguns autores discordam francamente da tendência geral de se interpretar geologicamente os parâmetros estatísticos. Objeções foram levantadas por Tucker \& Vacher (1980), que, ao estudarem 970 amostras 
de praias, dunas e rios, mostraram haver amplo recobrimento entre esses ambientes, que implicou grande probabilidade de erro na identificação de ambientes desconhecidos (incerteza de $25 \% \pm 15 \%$ se um dos três ambientes for eliminado por outros meios e de $35 \% \pm 15 \%$ em caso contrário). Jordan et al. (1981) mostraram também a ineficiência dos parâmetros granulométricos na caracterização das areias do Amazonas, neste caso devido às grandes dimensões e diversidade de ambientes do rio. Esses autores acham que as análises texturais podem dar resultados locais, em conjunto com outros fatores, conforme parece ser a linha proposta por Friedman em seus diversos trabalhos.

Finalmente MacLaren (1981) sugere que as características granulométricas de um depósito sedimentar dependem dos processos de: 1) remoção seletiva; 2) deposição seletiva; 3) deposição total; e 4) características da área-fonte. As proporções relativas dessas tendências poderiam ser observadas através dos três primeiros momentos e usadas na identificação de áreas-fontes e depósitos de um dado sistema ou ambiente, permitindo inferir direções de transporte. Exceções ocorreriam nesse modelo, altamente dedutivo, devido a: 1) existência de mais de uma área-fonte; 2) coesão dos finos; 3) floculação; e 4) variações granulométricas durante o transporte. Nota-se que as ressalvas 1 e 4 das exceções remetem a grande parte dos problemas que vêm sendo abordados por toda a bibliografia.

A contribuição específica deste trabalho - interpretação de dados granulométricos em quatro setores da costa brasileira - pode ser analisada, face à literatura internacional, considerando-se dois aspectos: a medição das propriedades dos grãos e sua interpretação. Pouco há que dizer quanto ao primeiro tópico: foram usadas as fórmulas de Folk \& Ward (1957) aplicadas a classes granulométricas por peso obtidas em análises granulométricas convencionais. Nestas, as classes são separadas em intervalos de $0,5 \phi$ para areias e $1 \phi$ para siltes e argilas. Conforme Swan et al. (1979), neste caso classes de $1 \phi$ seriam satisfatórios, postulado que não tivemos ainda ocasião de verificar com resultados analíticos de amostras reais.

No que se refere à interpretação, pudemos mostrar, para o universo de amostras considerado, que há uma relação definida entre desvio-padrão, assimetria e curtose, em função do diâmetro médio, ou seja, do intervalo granulométrico considerado. Mais uma vez cabe ressaltar que postulamos empiricamente o caráter de variável independente para o diâmetro médio.

As descontinuidades apontadas nos diagramas binários, que caracterizam populações distintas, foram já referidas por diversos autores para os valores de $+3,5 \phi,+3$ a $4 \phi$, $+4 \mathrm{a}+41 / 2 \phi$ e $+3 \mathrm{a}+5 \phi$ (Folk 1966). "A natureza aparentemente nos forneceu três populações modais dominantes: cascalho, areia mais silte grosso e argila, resultantes, respectivamente, de quebras diretas ao longo de juntas ou planos de acamamento, de desintegração granular e abrasão, e de transformações químicas" (Folk 1966, p. 81). As populações caracterizadas neste trabalho são de $0 \phi \mathrm{a}+2 \phi,+2 \phi$ a $+4 \phi$ e $+4 \phi$ a $+8 \phi$, que concordam tanto com a descontinuidade apontada pela literatura prévia em torno de $+4 \phi$ como com as populações naturais modais referidas por Folk (1966).

CONCLUSÕES É conveniente examinar a possibilidade de que as estatísticas sedimentológicas venham a se aproximar das estatísticas convencionais. Na presente situação, isto pode ser parcialmente obtido pelos cálculos feitos pelo método dos momentos em vez das fórmulas de Folk \& Ward (1957).

O uso empírico dos métodos estatísticos pode ser interessante, conforme mostraram resultados promissores de Folk \& Ward (1957), Passega (1957), Sahu (1964), Kovan (1966) e Fridman (1967), entre outros. Entretanto, a simples aplicação desses resultados deixa muitas dúvidas na interpretação, pois todas as linhas de investigação propostas estão ainda longe de apresentar resultados válidos universalmente.

O trabalho de Folk \& Ward (1957) já mostrava uma relação bem definida entre os valores das estatísticas granulométricas no intervalo $-3 \phi$ a $+3 \phi$, expressa por um helicóide. Em decorrência, alertavam esses autores, a escala qualitativa de graus de seleção deveria ser vista com reservas. Ampliamos, neste trabalho, o estudo das relações entre parâmetros granulométricos até $+8 \phi$ e pudemos verificar que há relações bem definidas entre desvio-padrão, assimetria, curtose e diâmetro médio no universo de amostras estudado. Em decorrência, concluímos que a ressalva feita por Folk \& Ward (1957) para o grau de seleção deva-se estender à assimetria e à curtose.

Agradecimentos $\mathrm{O}$ autor deseja expressar seus agradecimentos, pela leitura e sugestões apresentadas ao manuscrito, ao geólogo Antônio Fernando Gimenez e aos professores doutores Armando Márcio Coimbra, Kenitiro Suguio e Vicente José Fúlfaro; pela datilografia, às senhoras Bernardete de Lourdes Silva Pastore e Laurentina Maria de Andrade; e a Mário Otávio da Costa, pela preparação dos gráficos.

\section{REFERENNCIAS BIBLIOGRÁFICAS}

ASSEEZ, L.O. - 1972 - Triangular presentation of textural data in the interpretation of depositional environments. J. Sed. Petrol., 42(3):729-731.

CHAPPELL, J. - 1967 - Recognizing fossil strand lines from grain-size analysis. J. Sed. Petrol., 37(1):157-165.

CRONAN, C.S. - 1972 - Skewness and Kurtosis in polymodal sediments from the Irish Sea. J. Sed. Petrol., 42(1):102-107.

DOEGLAS, D.J. - 1968 - Grain-size indices, classification and environment. Sedimentology, 10(1):83-100.

DUANE, D.B. - 1964 - Significance of skewness in recent sediments, Western Pimlico Sound, North Carolina. J. Sed. Petrol., 34 (4): 864-874.

FOLK, R.L. - 1962 - Of skeness and sands. J. Sed. Petrol., 32(1): 145-156.
FOLK, R.L. - 1966 - A review of grain-size parameters. Sedimentology, 6(1):73-93.

FOLK, R.L. - 1968 - Petrology of sedimentary rocks. Austin, Hemphill's.

FOLK, R.L. \& WARD, W.C. - 1957 - Brazos River bar, a study in the significance of grain-size parameters. J. Sed. Petrol., 27 (1): 2-26.

FRIEDMAN, G.M. - 1967 - Dynamic processes and statistical parameters compared for size frequency distribution of beach and river sands. J. Sed. Petrol., 37(2):327-354.

FULFARO, V.J. \& PONÇANO, W.L. - 1976 - Sedimentação atual do estuário e Baía de Santos: um modelo geológico aplicado a projetos de expansão da zona portuária. In: CONGR. BRAS. GEOL. DE ENG., 1, Rio de Janeiro, 1976. Anais... Rio de Janeiro, ABGE. v. 2, p. 67-90. 
FULFARO, V.J.; PONÇANO, W.L.; GIMENEZ, A.F. - 1978 Sedimentação atual na foz do rio Potengi, Rio Grande do Norte: subsídios do planejamento da ampliação do porto. In: CONGR. BRAS. GEOL. DE ENG., 2, São Paulo, 1978. Anais... São Paulo, ABGE, v. 2, p. 85-110.

HAILS, J.R. - 1967 - Significance of statistical parameters for distinguishing sedimentary environments in New South Wales, Austrália. J. Sed. Petrol., 37(4):1059-1070.

HAILS, J.R. \& HOYT, J.H. - 1969 - The significance and limitations of statistical parameters for distinguishing ancient and modern sedimentary environments of the Lower Georgia Coastal Plain. J. Sed. Petrol., 39 (2):559-580.

INMAN, D.L. - 1952 - Measures for describing the size distribution of sediments. J. Sed. Petrol., 22 (3):125-145.

JORDAN, R.R.; BENSON, R.N.; SPOLIARIC, N. \& PICKETT, T.E. - 1978 - Discussion: skewness as a paleoenvironmental indicator. J. Sed. Petrol., 48(3):1000-1002.

JORDAN, D.W.; TOBIN, R.C.; LUNDEGARD, P.; SAMUELS, N.; SCHAUF, F.; THAELER, J.; VANBEUREN, V. \& POTTER, P.E. - 1981 - Comparison of methods of size analysis for sands of the Amazon-Solimões Rivers, Brazil and Peru. Sedimentology, 28(1):123-128.

KLOVAN, J.E. - 1966 - The use of factor analysis in determining depositional environments from grain-size distributions. J. Sed. Petrol., 36(1):115-125.

McLAREN, P. - 1981 - An interpretation of trends in grain-size measures. J. Sed. Petrol., 51 (2):611-625.

PASSEGA, R. - 1957 - Texture as characteristic of clastic deposition. Bull. A.A.P.G., 41 (9):1952-1984.

PONÇANO, W.L. \& FULFARO, V.J. - 1978 - Dynamic significance of grain-size parameters in coastal areas. In: INTER. CONGR. ENGIN. GEOL., 3, Madrid, 1978. Proceedings... Madrid, IAEG. v. 1 , sec. 2 , p. $268-277$.

PONÇANO, W.L.; FULFARO, V.J.; GIMENEZ, A.F. - 1976 Sedimentação atual na baía de Sepetiba, Estado do Rio de
Janeiro: contribuição e avaliação de viabilidade geotécnica da implantação de um porto. In: CONGR. BRAS. GEOL. ENG.,

1, Rio de Janeiro, 1976. Anais... Rio de Janeiro, ABGE. v. 2, p. $111-140$.

SAHU, B.K. - 1964 - Depositional mechanisms from the size analysis of clastic sediments. J. Sed. Petrol., 34(1):73-84.

SHEPARD, F.P. \& YOUNG, R. - 1961 - Distinguishing between beach and dune sands. J. Sed. Petrol., 31(2):196-214.

SWAN, D.; CLAQUE, J.J.; LUTERNAUER, J.L - 1978 Grain-size statistics. I: evaluation of the Folk and Ward graphic measures. J. Sed. Petrol., 48(3):863-878.

SWAN, D.; CLAQUE, J.J.; LUTERNAUER, J.L. - 1979 Grain-size statistics. II: evaluation of grouped moment measures. J. Sed. Petrol., 49(2):487-501.

TUCKER, R.E. \& VACHER, H.L. - 1980 - Effectiveness of discriminating beach dune, and river sands by moments and the cumulative weight percentages. J. Sed. Petrol., 50(1):165-173.

VALIA, H.S. \& CAMERON, B. - 1977 - Skewness as a paleoenvironmental indicator. J. Sed. Petrol., 47(2):784-793.

VALIA, H.S. \& CAMERON, B. - 1978 - Rephy: skewness as a paleoenvironmental indicator. J. Sed. Petrol., 48(3):1002-1004.

VAN ANDEL, T. \& POSTMA, H. - 1954 - Recent sediments of the Gulf of Paria. Amsterdam, North Holland Publ. v. 1.

VIARD, J.P. \& BREYER, J.A. - 1979 - Description and hydraulic interpretation of 'grain-size comulative curves from the Platte River system. Sedimentology, 26(3):427-439.

VISHER, G.S. - 1969 - Grain-size distributions and depositional processes. J. Sed. Petrol., 39 (3):1074-1106.

WINKELMOLEN, A.M. - 1982 - Critical remarks on grain parameters, with special emphasis on shape. Sedimentology, 29(2): 255-265.

MANUSCRITO

Recebido em 24 de junho de 1986 Revisão aceita em 27 de agosto de 1986

...toda vez que uma teoria é criada e testada, o conhecimento é o ganhador, independentemente de a teoria em si mesma permanecer ou cair. 